\title{
Analisis persepsi pengunjung terhadap fungsi Taman Kumbasari Tukad Badung, Denpasar Barat sebagai ruang terbuka non-hijau
}

\author{
Made Olga Alodia ${ }^{1}$, Cokorda Gede Alit Semarajaya ${ }^{1 *}$, I Made Sukewijaya²
}

1. Prodi Arsitektur Pertamanan, Fakultas Pertanian, Universitas Udayana, Indonesia 80232

2. Prodi Agroekoteknologi, Fakultas Pertanian, Universitas Udayana, Indonesia 80232

*E-mail: coksemarajaya@unud.ac.id

\begin{abstract}
Analysis of visitor perception to the function of Kumbasari Park, Tukad Badung, West Denpasar as non-green open space. Kumbasari Park is the result of the arrangement of Tukad Badung into a public nongreen open space that is used as a recreation place in the crowd of Denpasar City. This research aimed to determine and analyze visitors' perceptions of the function of Kumbasari Park as a non-green open space, as well as giving an input for the maintainer to improve the quality of Kumbasari Park in the future. The research method was surveyed through site observation, interviews, and questionnaires. The results of this research indicated that Kumbasari Park mainly functioned as the visual beauty of the city, and also functioned as a nongreen open space seen from the socio-cultural, ecological, economic, and architectural functions category. Some things related to Kumbasari Park that need attention was the issues of cleanliness, vandalism, aroma, vegetation, and facilities. Suggestions related to this research were facilities and management in Kumbasari Park needed to be improved to be able to attract visitors.
\end{abstract}

Keywords: function, non-green open space, perception, visual.

\section{Pendahuluan}

Ruang terbuka publik merupakan wadah bertemunya masyarakat dalam melakukan aktivitas sosial dan memungkinkan terjadinya interaksi sosial (Carr et al., 1992). Secara umum terdapat dua jenis ruang terbuka publik yaitu ruang terbuka hijau (RTH) dan ruang terbuka non-hijau (RTNH). Menurut Peraturan Menteri Pekerjaan Umum Nomor 12/Prt/M/2009, RTNH merupakan ruang terbuka di bagian wilayah perkotaan yang tidak termasuk dalam kategori RTH, berupa lahan yang diperkeras atau yang berupa badan air. Salah satunya yaitu Tukad Badung yang telah ditata menjadi tempat rekreasi yang bernama Taman Kumbasari dengan tujuan awal penataannya untuk mempermudah petugas Program Kali Bersih (Prokasih) dalam membersihkan kawasan Tukad Badung, pengelola juga menginginkan suatu ruang terbuka yang dapat digunakan masyarakat untuk berekreasi sekaligus memberikan edukasi untuk menjaga lingkungan sungai serta meningkatkan keindahan kawasan tersebut. Pemerintah Kota Denpasar menginginkan adanya aktivitas masyarakat yang positif pada tempat rekreasi bantaran sungai agar nantinya kesan kumuh dan seram menjadi hilang akibat aktivitas masyarakat tersebut (Pradipta dkk., 2018). Sebagai daya tarik baru perlu dilakukan pengamatan atau grand tour untuk mengetahui tempat tersebut lebih dalam, didapatkan fenomena yang menunjukkan Taman Kumbasari sepi pengunjung di pagi dan siang hari. Berdasarkan hal tersebut, maka penelitian melalui analisis persepsi pengunjung ini dilakukan, untuk dapat mengetahui fungsi dan persepsi pengunjung terhadap Taman Kumbasari sebagai RTNH. Diharapkan dengan penelitian ini dapat menggambarkan bagaimana penilaian dan harapan pengunjung selaku pengguna sehingga nantinya dapat menghasilkan rekomendasi terkait dengan pengelolaan dan penataan RTNH kedepannya maupun sebagai acuan jika nantinya akan dibuat tempat yang serupa.

\section{Metode}

Penelitian ini dilaksanakan di Taman Kumbasari, Tukad Badung (Jl. Gajah Mada, Dauh Puri Kangin, Denpasar Bali) selama lima bulan, mulai dari Februari hingga Juni 2019. Bahan dan alat yang digunakan dalam penelitian yaitu laptop, alat tulis, handphone, program Microsoft Office (Word, dan Excel), dan lembar 
kuesioner. Metode penelitian yang digunakan adalah metode survei dengan mengumpulkan data melalui observasi di lapangan, wawancara, dan kuesioner. Kuesioner diberikan kepada 40 responden yang merupakan pengunjung Taman Kumbasari dengan usia $\geq 17$ tahun serta dapat membaca dan menulis.

\subsection{Metode Analisis Data}

Metode analisis data meliputi tahap pengolahan data hasil observasi, wawancara, dan kuesioner dengan metode yang digunakan adalah tabulasi, pembobotan, dan analisis deskriptif.

1. Tabulasi

Metode pengolahan data hasil kuesioner dalam penelitian ini adalah tabulasi data dalam bentuk persentase (\%). Menurut Sudjana (2001), teknik tabulasi data ini digunakan untuk menghitung jumlah pilihan responden (f) dibandingkan dengan jumlah keseluruhan responden (N) ke dalam bentuk persentase (\%) dengan dikali 100 persen. Perhitungan seperti dikemukakan Sudjana (2001) adalah sebagai berikut:

$$
P=f / N \times 100 \%
$$

Keterangan:

$\mathrm{P}=$ Persentase

$\mathrm{f}=$ Frekuensi

$\mathrm{N}=\sum$ Total responden

2. Pembobotan

Setiap variabel penelitian diukur menggunakan instrumen pengukur dalam bentuk kuesioner berskala ordinal yang memenuhi pernyataan tipe Skala Likert. Menurut Sugiyono (2017) yang dimaksud dengan Skala Likert adalah skala yang digunakan untuk mengukur sikap, pendapat, dan persepsi seseorang atau sekelompok orang tentang fenomena sosial. Bobot nilai yang diberikan adalah sebagai berikut:

a. Sangat setuju $=5$

b. Setuju $=4$

c. Netral/cukup $=3$

d. $\quad$ Tidak setuju $=2$

e. Sangat tidak setuju $=1$

3. Analisis Deskriptif

Analisis deskriptif dilakukan dengan menganalisis data dengan cara mendeskripsikan atau menggambarkan data yang telah dikumpulkan.

\section{Hasil dan Pembahasan}

\subsection{Kondisi Tukad Badung dan Aspek Biofisik}

Tukad Badung merupakan salah satu sungai yang membelah Kota Denpasar dengan panjang total 17.5 km, dengan hulu di wilayah Kabupaten Badung dan hilimya sampai ke Teluk Benoa. Berdasarkan data Badan Meteorologi Klimatologi dan Geofisika (BMKG) tahun 2019, diperoleh rata-rata curah hujan bulanan dari tahun 2009 hingga 2018 sebesar $163,4 \mathrm{~mm}$ dengan suhu udara rata-rata sebesar $27,7^{\circ} \mathrm{C}$, lama penyinaran matahari rata-rata sebesar $67,4 \%$ dengan kelembaban udara rata-rata sebesar 78,8\%. Berdasarkan data yang diperoleh dari Balai Wilayah Sungai Bali-Penida tahun 2019, diperoleh debit air rata-rata dari tahun 2009 hingga 2018 sebesar 2,61 m³/dt di bagian hulu Tukad Badung dan sebesar 3,08 m²/dt untuk di bagian hilir Tukad Badung. Rata-rata tinggi muka air Tukad Badung berdasarkan pengukuran pada tahun 2016 dan 2017 yaitu sebesar 1,54 m.

Air Tukad Badung bersuhu 27,20 $\mathrm{C}$ dengan pH 6,82. Kualitas air menunjukkan bahwa DAS Tukad Badung memiliki tingkat kualitas air yang tergolong tercemar karena ditemukan beberapa kandungan yang dalam kelas mutu air dinyatakan B (cemar ringan) yaitu dissolved oxigen (DO), biological oxygen demand (BOD), ammonia (NH3), E.Coli, dan Coliforms. Kandungan dalam kelas mutu air D (cemar berat) yaitu fosfat $\left(\mathrm{PO}_{4}\right)$, cadmium $(\mathrm{Cd})$, chromium $(\mathrm{Cr})$, merkuri $(\mathrm{Hg})$ dan tembaga $(\mathrm{Cu})$ (Balai Wilayah Sungai Bali-Penida, 2019).

\subsection{Kondisi Umum Taman Kumbasari, Tukad Badung}

Taman Kumbasari ini terletak di kawasan Tukad Badung yang beralamat di Jl. Gajah Mada, Dauh Puri Kangin, Denpasar Bali, memiliki panjang 800 m namun untuk penataan pertama panjang Taman Kumbasari 
ini adalah $120 \mathrm{~m}$ dan dimanfaatkan sebagai ruang terbuka publik (Gambar 1). Penataan Taman Kumbasari bertujuan secara jangka panjang untuk mengubah pola pikir masyarakat agar tidak membuang sampah ke sungai dan memiliki manfaat sebagai salah satu cara untuk menumbuhkan kesadaran masyarakat agar menjaga kualitas lingkungan hidup dan menjaga fungsi sungai, sekaligus sebagai penyediaan ruang publik dan edukasi lingkungan yang bermanfaat untuk meningkatkan kualitas keindahan wajah kota. Taman Kumbasari berada di kawasan yang mempunyai nilai historis yang dahulu merupakan pusat pasar tradisional yang dikenal dengan "peken payuk" (pasar periuk) yang kini berkembang menjadi pasar tradisional modern yaitu Pasar Badung dan pusat bisnis di kota Denpasar yaitu kawasan Jl. Gajah Mada, serta Pasar Seni Kumbasari.

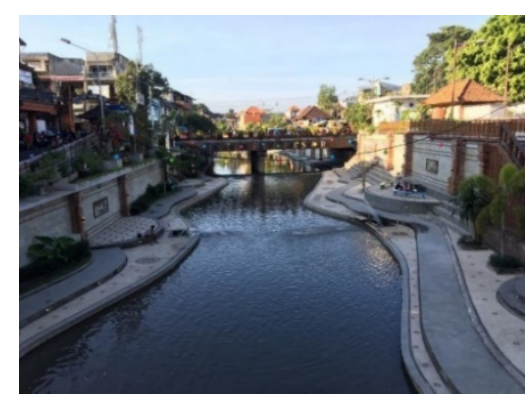

Gambar 1. Taman Kumbasari, Tukad Badung

Sebagai ruang publik Taman Kumbasari memiliki daya tarik kombinasi tampilan arsitektur Bali dan modern di antaranya seperti 1). Arsitektur Bali pada dinding dan pilarnya; 2). Penggunaan bahan-bahan alami seperti batu alam; 3). Penataan taman dengan penerangan eksotik (Gambar 2.b); 4). Air mancur bernuansa tradisional; 5). Desain perkerasan dengan lekuk dan karakter air yang dinamis; dan 6). Relief logo sign seeing Denpasar pada dinding sungai dengan penataan bernuansa tradisional yang menjadi salah satu obyek atau spot foto kenangan kunjungan ke Kota Denpasar ( Gambar 2.a). Selain fasilitas umum, Taman Kumbasari juga memiliki sarana dan prasarana inovatif penunjang seperti 1). Water level system berbasis sms gateway dan web; 2). Pemasangan alarm sebagai bagian dari early warning system (EWS); 3). Smart lighting; 4). Mural; 5). Taman gantung.

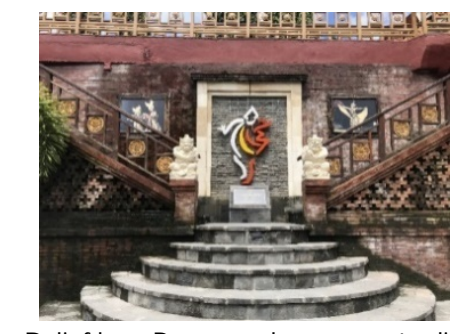

a.Relief logo Denpasar bernuansa tradisional

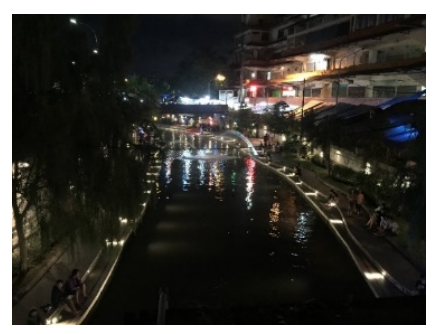

b.Penataan taman dengan penerangan eksotik Gambar 2. Daya Tarik Tampilan Taman Kumbasari, Tukad Badung

Taman Kumbasari, Tukad Badung dikelola oleh pemerintah Kota Denpasar yaitu Dinas Pekerjaan Umum Kota Denpasar. Dibentuk pasukan kebersihan yang diberi nama Prokasih berjumlah 10 orang untuk melakukan perawatan dan pembersihan di Taman Kumbasari. Adapun tugas dari Prokasih ini berkaitan dengan operasional dan pemeliharaan yang dilakukan secara rutin dan berkala. Pemeliharaan rutin yang dilakukan yaitu memelihara taman, membersihkan badan sungai dari sampah, pemeliharaan air mancur, pembersihan sedimentasi. Sedangkan pemeliharaan berkala yang dilakukan yaitu pemeliharaan sarana dan prasarana penunjang Taman Kumbasari, dan pemeliharaan dekorasi Taman Kumbasari.

\subsection{Inventarisasi Elemen Taman Kumbasari, Tukad Badung}

\subsubsection{Elemen Lunak (Softscape)}

Berdasarkan observasi yang telah dilakukan, didapat berbagai macam elemen lunak (softscape) yang hingga saat penelitian ini dilaksanakan masih dalam kondisi baik, dapat dilihat pada Tabel 1. 
Tabel 1. Inventarisasi Elemen Lunak

\begin{tabular}{cll}
\hline No & \multicolumn{1}{c}{ Nama Lokal } & \multicolumn{1}{c}{ Nama Latin } \\
\hline 1 & Paku Jejer & Nephrolepis sp. \\
2 & Alokasia & Alokasia sp. \\
3 & Kacapiring & Gardenia jasminoides \\
4 & Puring Anting Raja & Codiaeum sp. \\
5 & Puring Kerupuk & Codiaeum sp. \\
6 & Puring Mas Koki & Codiaeum sp. \\
7 & Hanjuang & Cordyline terminalis \\
8 & Kamboja & Plumeria rubra \\
9 & Palem Ekor Tupai & Wodyetia bifurcata \\
10 & Ketapang Kencana & Terminalia mantaly \\
11 & Bugenvil & Bougainvillea sp. \\
12 & Lee Kwan Yew & Veronia elliptica \\
13 & Daun Pilo & Philodendron selloum \\
14 & Kembang Sepatu & Hibiscus rosa-sinensis L. \\
15 & Rumput Gajah Mini & Axonopus compressus \\
16 & Keladi Hias & Caladium sp. \\
17 & Ruellia & Ruellia malacosperma \\
18 & Peace Lily & Spathiphyllum sp. \\
19 & Iron Plant & Aspidistra elatior \\
\hline
\end{tabular}

\subsubsection{Elemen Keras (Hardscape)}

Berdasarkan observasi yang telah dilakukan, didapat berbagai macam elemen keras (hardscape) beserta kondisinya yang dapat dilihat pada Tabel 2 .

Tabel 2. Inventarisasi Elemen Keras

\begin{tabular}{clcc}
\hline No & & Jumlah & Kondisi \\
\hline 1 & Air Mancur & 5 & Baik \\
2 & Lampu Taman & 32 & Rusak Ringan \\
3 & Lampu Gantung & 6 & Rusak Ringan \\
4 & Bangku Taman & 17 & Baik \\
5 & Meja Taman & 3 & Baik \\
6 & Tempat Sampah & 5 & Rusak Ringan \\
7 & Foto Hiasan Dinding & 10 & Rusak Ringan \\
8 & Ornamen & 2 & Baik \\
9 & Tugu Peresmian & 1 & Baik \\
10 & Logo Sign Denpasar & 3 & Baik \\
11 & Tangga Besi & 2 & Rusak Ringan \\
12 & Patung & 2 & Baik \\
13 & Lampu Sorot Bingkai & 10 & Baik \\
14 & Pot & 2 & Baik \\
15 & Jembatan Penghubung & 1 & Baik \\
\hline
\end{tabular}

\subsection{Latar Belakang Responden Taman Kumbasari, Tukad Badung}

Berdasarkan hasil kuesioner yang diberikan kepada 40 responden, dapat dijelaskan bahwa responden yang merupakan pengunjung Taman Kumbasari terdiri atas 50\% laki-laki dan 50\% perempuan yang dominan berusia $17-24$ tahun (70\%), dengan pendidikan terakhir SMA $(67,5 \%)$ dan memiliki pekerjaan utama yang sebagai pegawai swasta (52,5\%).

\subsection{Kunjungan dan Persepsi Terhadap Taman Kumbasari, Tukad Badung}

Menurut hasil yang diperoleh, frekuensi kunjungan dominan dari responden yaitu baru pertama kali mengunjungi Taman Kumbasari (57,5\%) dengan lama kunjungan di bawah 1 jam (50\%). Keberadaan Taman Kumbasari ini menciptakan berbagai macam persepsi terkait faktor pendorong responden untuk berkunjung. Faktor pendorong yang diperoleh yaitu karena ingin melihat-lihat (60\%). Menurut responden, Taman Kumbasari indah (52,5\%) dengan faktor penyebab adalah objek yang menarik (45\%) dan keadaan yang cukup 
terawat $(67,5 \%)$. Adapun daya tarik objek yang menurut responden menjadi spot favorit yang dapat dilakukan repetisi yaitu taman (47,5\%), mural (55\%), air mancur berwarna dan lampu-lampu (47,5\%).

\subsection{Persepsi Mengenai Fungsi Taman Kumbasari}

Berdasarkan observasi yang telah dilakukan, didapat beberapa persepsi pengunjung mengenai fungsi dari Taman Kumbasari yang dapat dilihat pada tabel 3.

Tabel 3. Persepsi Mengenai Fungsi Taman Kumbasari

\begin{tabular}{|c|c|c|c|c|c|c|c|c|c|}
\hline \multicolumn{10}{|c|}{ Persentase dan bobot penilaian $(+)$} \\
\hline No & Fungsi & $\begin{array}{l}\text { STS } \\
(1)\end{array}$ & $\begin{array}{l}\text { TS } \\
(2)\end{array}$ & $\begin{array}{l}N \\
(3)\end{array}$ & $\begin{array}{l}\text { SE } \\
(4)\end{array}$ & $\begin{array}{l}\text { SSE } \\
(5)\end{array}$ & $\begin{array}{l}\text { Jumlah } \\
\text { skor }\end{array}$ & $\begin{array}{c}\text { Index } \\
\%\end{array}$ & Keterangan \\
\hline 1 & $\begin{array}{l}\text { Lokasi Taman Kumbasari mudah } \\
\text { dijangkau }\end{array}$ & 0 & 5 & 12 & 20 & 3 & 141 & 70,5 & Setuju \\
\hline 2 & $\begin{array}{l}\text { Fasilitas parkir yang disediakan di } \\
\text { taman sudah memadai }\end{array}$ & 2 & 9 & 6 & 20 & 3 & 133 & 66,5 & Setuju \\
\hline 3 & $\begin{array}{l}\text { Sampah-sampah di Taman } \\
\text { Kumbasari sudah berada pada } \\
\text { tempatnya }\end{array}$ & 4 & 13 & 10 & 11 & 2 & 114 & 57 & $\begin{array}{l}\text { Cukup } \\
\text { Setuju }\end{array}$ \\
\hline 4 & $\begin{array}{l}\text { Aroma disekitar sungai tidak } \\
\text { mengganggu kenyamanan }\end{array}$ & 20 & 10 & 4 & 4 & 2 & 78 & 39 & Tidak Setuju \\
\hline 5 & $\begin{array}{l}\text { Tanaman di Taman Kumbasari sudah } \\
\text { tertata rapi dan indah }\end{array}$ & 0 & 3 & 13 & 22 & 2 & 143 & 71,5 & Setuju \\
\hline 6 & $\begin{array}{l}\text { Areal Taman Kumbasari sudah } \\
\text { melindungi anda dari paparan sinar } \\
\text { matahari langsung }\end{array}$ & 12 & 20 & 6 & 1 & 1 & 79 & 39,5 & Tidak Setuju \\
\hline 7 & Fasilitas di taman sudah memadai & 1 & 10 & 20 & 7 & 2 & 119 & 59,5 & $\begin{array}{l}\text { Cukup } \\
\text { Setuju }\end{array}$ \\
\hline 8 & $\begin{array}{l}\text { Pedagang makanan merupakan } \\
\text { fasilitas penting }\end{array}$ & 11 & 22 & 5 & 2 & 0 & 78 & 39 & Tidak Setuju \\
\hline 9 & $\begin{array}{l}\text { Secara keseluruhan anda sudah } \\
\text { merasa nyaman berada di Taman } \\
\text { Kumbasari }\end{array}$ & 4 & 6 & 21 & 7 & 2 & 117 & 58,5 & $\begin{array}{l}\text { Cukup } \\
\text { Setuju }\end{array}$ \\
\hline
\end{tabular}

Keterangan: STS (Sangat Tidak Setuju), TS (Tidak Setuju), N (Netral/Cukup Setuju),

SE (Setuju), SSE (Sangat Setuju)

\subsection{Fungsi Taman Kumbasari Sebagai RTNH}

Taman Kumbasari merupakan salah satu ruang publik yang masuk dalam kategori Ruang Terbuka Non Hijau (RTNH) dan memiliki beragam fungsi. Fungsi Taman Kumbasari diidentifikasi dengan menggunakan acuan fungsi Ruang Terbuka Non Hijau (RTNH) menurut Peraturan Menteri Pekerjaan Umum Nomor 12/Prt/M/2009 yang terbagi menjadi kategori fungsi sosial budaya, fungsi ekologis, fungsi ekonomis, dan fungsi arsitektural (Tabel 4).

\subsubsection{Fungsi Sosial Budaya}

Berdasarkan observasi yang telah dilakukan, untuk kategori fungsi sosial budaya di Taman Kumbasari dapat dilihat pada tabel 4 .

Tabel 4. Fungsi Sosial Budaya Taman Kumbasari

\begin{tabular}{clcccccccc}
\hline No. & \multicolumn{1}{c}{ Fungsi RTNH } & $\begin{array}{c}\text { STS } \\
(1)\end{array}$ & $\begin{array}{c}\text { TS } \\
\text { (2) }\end{array}$ & $\begin{array}{c}\text { (3) } \\
\text { (3) }\end{array}$ & $\begin{array}{c}\text { SE } \\
\text { (4) }\end{array}$ & $\begin{array}{c}\text { SSE } \\
(5)\end{array}$ & $\begin{array}{c}\text { Jumlah } \\
\text { skor }\end{array}$ & $\begin{array}{c}\text { Index } \\
\%\end{array}$ & Keterangan \\
\hline 1. & $\begin{array}{l}\text { Fungsi Sosial Budaya } \\
\begin{array}{l}\text { Taman Kumbasari berfungsi } \\
\text { sebagai wadah aktivitas sosial } \\
\text { budaya masyarakat. }\end{array}\end{array}$ & 1 & 1 & 14 & 19 & 5 & 146 & 73 & Setuju \\
2. & $\begin{array}{l}\text { Taman Kumbasari berfungsi } \\
\text { sebagai pengungkapan ekspresi } \\
\text { budaya atauk kultur lokal. }\end{array}$ & 0 & 5 & 15 & 17 & 3 & 138 & 69 & Setuju \\
3aman Kumbasari berfungsi \\
$\begin{array}{l}\text { sebagai media komunikasi } \\
\text { warga kota. }\end{array}$
\end{tabular}




\begin{tabular}{clcccccccc}
\hline No. & \multicolumn{1}{c}{ Fungsi RTNH } & $\begin{array}{c}\text { STS } \\
(1)\end{array}$ & $\begin{array}{c}\text { TS } \\
(2)\end{array}$ & $\begin{array}{c}\text { N } \\
(3)\end{array}$ & $\begin{array}{c}\text { SE } \\
(4)\end{array}$ & $\begin{array}{c}\text { SSE } \\
(5)\end{array}$ & $\begin{array}{c}\text { Jumlah } \\
\text { skor }\end{array}$ & $\begin{array}{c}\text { Index } \\
\%\end{array}$ & Keterangan \\
\hline 4. & $\begin{array}{l}\text { Taman Kumbasari berfungsi } \\
\text { sebagai tempat olahraga. }\end{array}$ & 9 & 25 & 4 & 2 & 0 & 79 & 39,5 & $\begin{array}{c}\text { Tidak } \\
\text { Setuju }\end{array}$ \\
5. & $\begin{array}{l}\text { Taman Kumbasari berfungsi } \\
\text { sebagai tempat rekreasi. }\end{array}$ & 0 & 2 & 6 & 24 & 8 & 158 & 79 & Setuju \\
6. & $\begin{array}{l}\text { Taman Kumbasari mampu } \\
\text { berfungsi sebagai wadah dan } \\
\text { objek pendidikan, penelitian, } \\
\text { dan sejenisnya. }\end{array}$ & 0 & 2 & 9 & 23 & 6 & 153 & 76,5 & Setuju \\
\hline Keterangan: STS (Sangat Tidak Setuju), TS (Tidak Setuju), N (Netral/Cukup Setuju), SE (Setuju), SSE (Sangat Setuju)
\end{tabular}

Hasil yang menunjukkan responden setuju Taman Kumbasari berfungsi sebagai tempat rekreasi dengan total skor $158(79 \%)$ pada poin 5 (Tabel 4) tersebut didukung dengan hasil observasi persepsi responden mengenai tujuan kunjungan ke Taman Kumbasari yang sebagian besar untuk berekreasi atau berwisata sebesar $80 \%$ hal tersebut karena Taman Kumbasari ini merupakan ruang terbuka dengan memanfaatkan sungai yang dirubah menjadi daya tarik baru untuk berekreasi (Tabel 5).

Tabel 5. Tujuan Kunjungan Ke Taman Kumbasari, Tukad Badung

\begin{tabular}{lc}
\hline \multicolumn{1}{c}{ Tujuan Kunjungan } & Persentase (\%) \\
\hline Berekreasi/Berwisata & 80 \\
Belajar/Penelitian & 5 \\
Bisnis & 2,5 \\
Lainnya & 12,5 \\
\hline Total & 100 \\
\hline
\end{tabular}

Hasil yang menunjukkan responden setuju Taman Kumbasari berfungsi sebagai media komunikasi warga kota dengan total skor 143 (71,5\%) pada poin 3 (Tabel 4) tersebut didukung dengan hasil observasi persepsi responden mengenai sumber informasi yang diperoleh mengenai Taman Kumbasari, yaitu sebagian besar dari internet sebesar 55\% dan dari teman/kerabat sebesar 42,5\% (Tabel 6).

Tabel 6. Sumber Informasi Mengenai Taman Kumbasari, Tukad Badung

\begin{tabular}{lc}
\hline \multicolumn{1}{c}{ Sumber Informasi } & Persentase (\%) \\
\hline Teman/Kerabat & 42,5 \\
Televisi & 2,5 \\
Internet & 55 \\
Koran & 0 \\
\hline Total & 100 \\
\hline
\end{tabular}

Untuk fungsi pada poin 6 (Tabel 13) yaitu Taman Kumbasari mampu berfungsi sebagai wadah dan objek pendidikan, penelitian, dan sejenisnya didukung dengan berlangsungnya beberapa kegiatan di Taman Kumbasari yang memberikan edukasi terkait lingkungan sungai yang sangat penting dilakukan untuk menumbuhkan kesadaran masyarakat agar menjaga kualitas dan manfaat lingkungan sungai, sehingga nantinya mampu menciptakan lingkungan yang bersih dan sehat. Beberapa kegiatan tersebut diantaranya pameran pemanfaatan barang bekas oleh komunitas dari STID, pagelaran wayang bertema menjaga lingkungan sungai, lomba menggambar dan mewarnai bertema menjaga lingkungan sungai, pameran kontemporer tentang lingkungan sungai oleh mahasiswa ISI Denpasar, outbond dari Teruna Teruni Denpasar sekaligus melakukan pembersihan di area Taman Kumbasari, dan kunjungan dari sekolah-sekolah untuk melakukan pembersihan sekaligus edukasi lingkungan sungai.

Mengenai fungsi sosial budaya ini disimpulkan bahwa Taman Kumbasari telah berfungsi dalam aspek sosial budaya karena keberadaannya mendukung aktivitas sosial budaya, berfungsi sebagai media komunikasi warga kota, serta berfungsi sebagai tempat rekreasi dan objek pendidikan. Namun dalam fungsi ini terdapat satu fungsi yang tidak berjalan, yaitu Taman Kumbasari tidak berfungsi sebagai tempat olahraga karena 
menurut pengunjung, luasan Taman Kumbasari tidak memungkinkan untuk pengunjung dapat melakukan aktivitas tersebut.

\subsubsection{Fungsi Ekologis}

Berdasarkan observasi yang telah dilakukan, untuk kategori fungsi ekologis di Taman Kumbasari dapat dilihat pada tabel 7 .

Tabel 7. Fungsi Ekologis Taman Kumbasari

\begin{tabular}{clcccccccc}
\hline No. & \multicolumn{1}{c}{ Fungsi RTNH } & $\begin{array}{c}\text { STS } \\
\text { (1) }\end{array}$ & $\begin{array}{c}\text { TS } \\
(2)\end{array}$ & $\begin{array}{c}\text { N } \\
\text { (3) }\end{array}$ & $\begin{array}{c}\text { SE } \\
\text { (4) }\end{array}$ & $\begin{array}{c}\text { SSE } \\
\text { (5) }\end{array}$ & $\begin{array}{c}\text { Jumlah } \\
\text { skor }\end{array}$ & $\begin{array}{c}\text { Index } \\
\%\end{array}$ & Keterangan \\
\hline 1. & $\begin{array}{l}\text { Fungsi Ekologis } \\
\begin{array}{l}\text { Taman Kumbasari menciptakan } \\
\text { sistem sirkulasi udara dan air } \\
\text { secara lancar. }\end{array}\end{array}$ & 1 & 9 & 22 & 6 & 2 & 119 & 59,5 & $\begin{array}{l}\text { Cukup } \\
\text { Setuju }\end{array}$ \\
2. & $\begin{array}{l}\text { Taman Kumbasari berfungsi } \\
\text { dalam penyerapan air hujan. }\end{array}$ & 10 & 23 & 5 & 2 & 0 & 79 & 39,5 & $\begin{array}{l}\text { Tidak } \\
\text { Setuju }\end{array}$ \\
\hline Keterangan: STS (Sangat Tidak Setuju), TS (Tidak Setuju), N (Netral/Cukup Setuju), SE (Setuju), SSE (Sangat Setuju)
\end{tabular}

Hasil yang menunjukkan responden cukup setuju Taman Kumbasari menciptakan sistem sirkulasi udara dan air secara lancar dengan total skor $119(59,5 \%)$ pada poin 1 (Tabel 7) tersebut berkaitan dengan hasil observasi persepsi responden mengenai kondisi lingkungan di Taman Kumbasari yang dominan menunjukkan kondisi cukup nyaman sebesar 52,5\% (Tabel 8). Dalam hal ini didukung oleh pernyataan yang terlibat tidak hanya masalah fisik biologis, namun juga perasaan, suara, cahaya, aroma, dan suhu rangsangan ditangkap sekaligus, lalu diolah oleh otak, kemudian otak akan memberikan penilaian relatif apakah kondisi itu nyaman atau tidak (Satwiko, 2009).

Tabel 8. Kondisi Lingkungan di Taman Kumbasari, Tukad Badung

\begin{tabular}{|c|c|}
\hline Kondisi Lingkungan & Persentase (\%) \\
\hline Tidak nyaman & 12,5 \\
\hline Cukup nyaman & 52,5 \\
\hline Nyaman & 30 \\
\hline Sangat nyaman & 5 \\
\hline Total & 100 \\
\hline
\end{tabular}

Tak hanya berhubungan dengan persepsi mengenai kondisi lingkungan di Taman Kumbasari, fungsi pada poin 1 (Tabel 7) tersebut juga berhubungan dengan hasil observasi persepsi responden mengenai kebersihan Taman Kumbasari yang dominan didapatkan hasil yaitu kotor sebesar 60\% karena masih banyaknya sampah bawaan di sepanjang aliran sungai dan banyak juga pedagang sekitar serta pengunjung yang membuang sampah di areal Taman Kumbasari. Hal tersebut menyebabkan lingkungan menjadi tidak bersih (Tabel 9).

Tabel 9. Kebersihan Taman Kumbasari, Tukad Badung

\begin{tabular}{lcc}
\hline & Kebersihan & Persentase (\%) \\
\hline Sangat kotor & 0 \\
Kotor & 60 \\
Bersih & 40 \\
Sangat bersih & 0 \\
\hline Total & 100 \\
\hline
\end{tabular}

Mengenai fungsi ekologis ini dapat disimpulkan bahwa Taman Kumbasari belum mampu berfungsi dalam aspek ekologis karena sistem sirkulasi udara dan air belum lancar diakibatkan masih adanya pencemaran udara dan air di lingkungan Taman Kumbasari, dalam fungsi ekologis ini terdapat fungsi yang tidak berjalan yaitu Taman Kumbasari tidak berfungsi dalam penyerapan air hujan hal tersebut disebabkan karena hampir keseluruhan area didominasi oleh perkerasan, sehingga pada saat hujan turun air tersebut tidak mampu terserap ke dalam tanah.

\subsubsection{Fungsi Ekonomis}

Berdasarkan observasi yang telah dilakukan, untuk kategori fungsi ekonomis di Taman Kumbasari dapat dilihat pada tabel 10 . 
Tabel 10. Fungsi Ekonomis Taman Kumbasari

\begin{tabular}{|c|c|c|c|c|c|c|c|c|c|}
\hline No. & Fungsi RTNH & $\begin{array}{l}\text { STS } \\
(1)\end{array}$ & $\begin{array}{l}\text { TS } \\
\text { (2) }\end{array}$ & $\begin{array}{l}\mathrm{N} \\
(3)\end{array}$ & $\begin{array}{l}\text { SE } \\
(4)\end{array}$ & $\begin{array}{l}\text { SSE } \\
(5)\end{array}$ & $\begin{array}{l}\text { Jumlah } \\
\text { skor }\end{array}$ & $\begin{array}{c}\text { Index } \\
\%\end{array}$ & Keterangan \\
\hline & Fungsi Ekonomis & & & & & & & & \\
\hline 1. & $\begin{array}{l}\text { Taman Kumbasari memiliki nilai } \\
\text { jual dari sarana parkir. }\end{array}$ & 3 & 8 & 19 & 10 & 0 & 116 & 58 & $\begin{array}{l}\text { Cukup } \\
\text { Setuiu }\end{array}$ \\
\hline 2. & $\begin{array}{l}\text { Taman Kumbasari memiliki nilai } \\
\text { jual dari sarana olahraga. }\end{array}$ & 9 & 25 & 4 & 2 & 0 & 79 & 39,5 & $\begin{array}{l}\text { Tidak } \\
\text { Setuju }\end{array}$ \\
\hline 3. & $\begin{array}{l}\text { Taman Kumbasari memiliki nilai } \\
\text { jual dari sarana bermain }\end{array}$ & 10 & 24 & 4 & 2 & 0 & 78 & 39 & $\begin{array}{l}\text { Tidak } \\
\text { Setuju }\end{array}$ \\
\hline 4. & $\begin{array}{l}\text { Taman Kumbasari dimanfaatkan } \\
\text { untuk mengakomodasi } \\
\text { pemberdayaan usaha kecil. }\end{array}$ & 3 & 12 & 17 & 7 & 0 & 106 & 53 & $\begin{array}{l}\text { Cukup } \\
\text { Setuju }\end{array}$ \\
\hline
\end{tabular}

Berdasarkan tabel tersebut diatas, didapat hasil bahwa Taman Kumbasari cukup berfungsi dalam aspek ekonomis. Taman Kumbasari memiliki nilai jual dari sarana parkir dan cukup mengakomodasi pemberdayaan usaha kecil. Namun dari tabel tersebut terdapat fungsi yang tidak berjalan yaitu Taman Kumbasari tidak memiliki nilai jual dari sarana olahraga dan sarana bermain.

\subsubsection{Fungsi Arsitektural}

Berdasarkan observasi yang telah dilakukan, untuk kategori fungsi arsitektural di Taman Kumbasari dapat dilihat pada tabel 11 .

Tabel 11. Fungsi Arsitektural Taman Kumbasari

\begin{tabular}{cccccccccc}
\hline No. & \multicolumn{1}{c}{ Fungsi RTNH } & $\begin{array}{c}\text { STS } \\
(1)\end{array}$ & $\begin{array}{c}\text { TS } \\
(2)\end{array}$ & $\begin{array}{c}\text { N } \\
(3)\end{array}$ & $\begin{array}{c}\text { SE } \\
(4)\end{array}$ & $\begin{array}{c}\text { SSE } \\
(5)\end{array}$ & $\begin{array}{c}\text { Jumlah } \\
\text { skor }\end{array}$ & $\begin{array}{c}\text { Index } \\
\%\end{array}$ & Keterangan \\
\hline 1. & $\begin{array}{l}\text { Fungsi Arsitektural } \\
\begin{array}{l}\text { Taman Kumbasari } \\
\text { meningkatkan kenyamanan dan } \\
\text { memperindah lanskap kota. }\end{array}\end{array}$ & 1 & 1 & 6 & 22 & 10 & 159 & 79,5 & Setuju \\
2. & $\begin{array}{l}\text { Taman Kumbasari dapat } \\
\text { menstimulasi kreativitas dan } \\
\text { produktivitas warga kota. }\end{array}$ & 0 & 2 & 11 & 19 & 8 & 153 & 76,5 & Setuju \\
3aman Kumbasari menjadi \\
$\begin{array}{l}\text { salah satu pembentuk faktor } \\
\text { keindahan arsitektural. } \\
\text { Taman Kumbasari menciptakan } \\
\text { suasana serasi antara area } \\
\text { terbangun dan tidak terbangun. }\end{array}$ & 0 & 2 & 11 & 19 & 8 & 153 & 76,5 & Setuju \\
\hline Keterangan: STS (Sangat Tidak Setuju), TS (Tidak Setuju), N (Netral//Cukup Setuju), SE (Setuju), SSE (Sangat Setuju)
\end{tabular}

Hasil yang menunjukkan responden setuju Taman Kumbasari meningkatkan kenyamanan dan memperindah lanskap kota dengan total skor 159 (79,5\%) pada poin 1 (Tabel 11) dan responden setuju Taman Kumbasari menjadi salah satu pembentuk faktor keindahan arsitektural dengan total skor 153 (76,5\%) pada poin 3 (Tabel 11) tersebut didukung dengan hasil observasi persepsi responden mengenai waktu kunjungan ke Taman Kumbasari yang dibagi menjadi empat waktu yaitu pagi, siang, sore, dan malam. Pengunjung terbanyak yaitu pada saat malam hari sebanyak $45 \%$, dan sore hari sebanyak 35\% (Tabel 12). Taman Kumbasari memiliki desain arsitektur Bali dan modern dimana pada sore dan malam hari akan terlihat semakin indah karena didukung dengan adanya lampu-lampu dan air mancur berwarna yang menimbulkan daya tarik. Tabel 12. Waktu Kunjungan Ke Taman Kumbasari, Tukad Badung

\begin{tabular}{lcc}
\hline & Waktu Kunjungan & Persentase (\%) \\
\hline Pagi hari & 7,5 \\
Siang hari & 12,5 \\
Sore hari & 35 \\
Malam hari & 45 \\
\hline Total & 100 \\
\hline
\end{tabular}


Selain didukung dengan hasil observasi persepsi responden mengenai waktu kunjungan ke Taman Kumbasari, fungsi arsitektural tersebut juga didukung dengan hasil observasi persepsi responden mengenai fungsi utama Taman Kumbasari yaitu sebagai keindahan visual di tengah kota sebesar 75\% karena Taman Kumbasari memiliki desain yang indah seperti kombinasi tampilan dengan arsitektur Bali dan modern (Tabel 13).

Tabel 13. Fungsi Utama Taman Kumbasari, Tukad Badung

\begin{tabular}{lc}
\hline \multicolumn{1}{c}{ Fungsi Utama } & Persentase (\%) \\
\hline Tempat bersosialisasi & 20 \\
Pendidikan & 2,5 \\
Tempat olahraga dan bermain & 2,5 \\
Keindahan visual di tengah kota & 75 \\
\hline Total & 100 \\
\hline
\end{tabular}

Mengenai fungsi arsitektural ini dapat disimpulkan bahwa Taman Kumbasari telah berfungsi baik dalam fungsi arsitektural dan mampu menjadi daya tarik baru sebagai tempat rekreasi di tengah Kota Denpasar.

\subsection{Rekomendasi untuk peningkatan Taman Kumbasari sebagai RTNH}

Berdasarkan hasil yang diperoleh, ditemukan beberapa permasalahan yang perlu mendapat perhatian dari pihak pengelola agar mampu meningkatkan kualitas ataupun fungsi dari Taman Kumbasari seperti aroma tidak sedap, kebersihan, vandalisme dan keamanan, kurangnya peneduh, dan perlunya penambahan fasilitas. Peneliti memberikan beberapa rekomendasi terkait permasalahan yang didapatkan di lapangan.

Untuk dapat mengurangi aroma tidak sedap, perlu ditambahkan vegetasi yang memiliki aroma harum seperti sedap malam (Polianthes tuberosa), melati putih (Jasminum sambac), dan kacapiring (Gardenia jasminoides) sebagai pengalihan terhadap aroma tidak sedap di Taman Kumbasari. Untuk permasalahan kebersihan ditambahkan tempat sampah, dan menambah petugas kebersihan (prokasih). Begitu juga dengan permasalahan vandalisme dan keamanan bisa dengan mengadakan petugas untuk berjaga, menyediakan pelampung, memasang CCTV (closed circuit television), menambahkan rambu-rambu aturan dan larangan, serta menambahkan jalur evakuasi di beberapa titik untuk tambahan akses dan keadaan darurat.

Berdasarkan hasil wawancara didapatkan penyebab mengapa Taman Kumbasari sepi di pagi dan siang hari yaitu salah satunya karena kondisi taman yang panas karena kurangnya naungan, mengenai hal tersebut dapat direkomendasikan dengan menambahkan pergola yang dikombinasikan dengan tanaman di beberapa titik di Taman Kumbasari dengan fungsi sebagai naungan di siang hari dan menambah keindahan taman (Gambar 3).

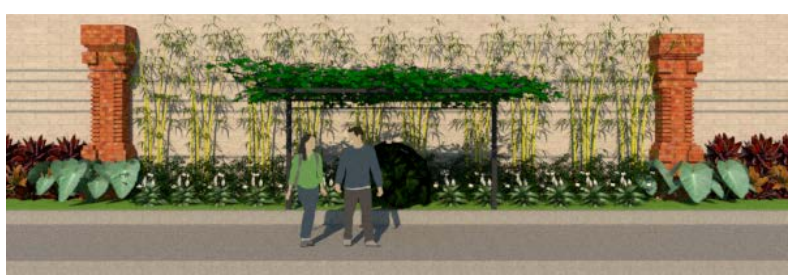

a. Rekomendasi Pergola dan Penataan Tampak Depan

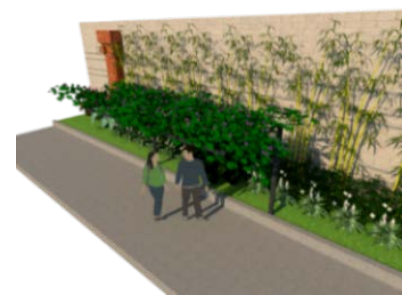

b. Rekomendasi Pergola dan Penataan Tampak Samping

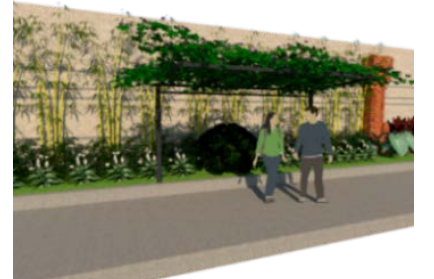

c. Rekomendasi Pergola dan Penataan Tampak Samping

Gambar 3. Rekomendasi Pergola dan Penataan Taman 
Penambahan tanaman lainnya yang berfungsi untuk kehidupan satwa di Taman Kumbasari juga diperlukan untuk keseimbangan ekosistem sungai, seperti penambahan tanaman berbunga yang mampu mengundang satwa seperti lebah, kupu-kupu, capung, maupun burung. Sedangkan untuk penambahan fasilitas pendukung diperlukan beberapa bangku taman dan lampu taman di Taman Kumbasari.

\section{Simpulan dan Saran \\ 4.1 Simpulan}

Persepsi pengunjung menunjukkan bahwa fungsi utama Taman Kumbasari yaitu sebagai keindahan visual, karena Taman Kumbasari ini memiliki desain arsitektur Bali dan modern. Secara umum Taman Kumbasari sebagai ruang terbuka non-hijau (RTNH) telah berfungsi dalam kategori sosial budaya, ekologis, ekonomis, dan arsitektural. Namun masih ada fungsi yang belum berjalan seperti Taman Kumbasari tidak berfungsi sebagai tempat olahraga, tidak berfungsi dalam hal penyerapan air hujan, tidak memiliki nilai jual dari sarana olahraga dan tidak memiliki nilai jual dari sarana bermain. Sebagai ruang terbuka non-hijau (RTNH), didapat persepsi pengunjung mengenai keadaan Taman Kumbasari secara keseluruhan yaitu cukup terawat, nyaman, dan aman.

\subsection{Saran}

Tujuan utama dan fokus perhatian pengunjung adalah berekreasi. Tentunya kenyamanan, kebersihan, dan keamanan yang diinginkan pengunjung. Oleh karena itu pengelola sebaiknya perlu meningkatkan kualitas kenyamanan, kebersihan, dan kemanan tersebut dengan melakukan perbaikan serta penambahan sarana prasarana, agar dapat menarik minat pengunjung untuk datang ke Taman Kumbasari. Selain itu menarik minat pengunjung juga bisa dengan meningkatkan nilai eksistensi dan mengangkat fungsi edukasi lingkungan, dengan mengadakan kegiatan sosial maupun hiburan yang sekaligus mengusung ajakan agar pengunjung dan masyarakat turut serta dalam menjaga lingkungan sungai. Perihal aroma tidak sedap dan panas terik matahari perlu ditambahkan pergola dan tanaman yang mampu membantu memperbaiki aroma disekitar. Disarankan kepada pengunjung untuk menghindari kontak fisik secara langsung dengan air sungai karena mengalami pencemaran dan ditemukan beberapa kandungan berbahaya. Diharapkan ada penelitian lanjutan yang berfokus terhadap bagaimana cara memperbaiki kualitas dan kuantitas air sungai yang tercemar di Taman Kumbasari.

\section{Daftar Pustaka}

Badan Meteorologi Klimatologi dan Geofisika (BMKG). 2019. Pelayanan Jasa Informasi Klimatologi Data Unsur IKlim Bulanan. Balai Besar Badan Meteorologi Klimatologi dan Geofisika Wilayah III. Denpasar.

Balai Wilayah Sungai Bali-Penida. 2019. Data Kondisi dan Kualitas Kuantitas Air Tukad Badung. Denpasar. Bali

Carr, S., Francis, M., Rivlin, L. G., \& Stone, A. M. (1992). Public space. Cambridge University Press. Australia.

Dinas Pekerjaan Umum dan Penataan Ruang Kota Denpasar. 2019. Data Kondisi Taman Kumbasari dan Standarisasi Pengelolaan. Denpasar. Bali.

Peraturan Menteri Pekerjaan Umum Nomor. 12/PRT/M/2009 tentang Pedoman Penyediaan dan Pemanfaatan Ruang Terbuka Non Hijau di Wilayah Kota/Kawasan Perkotaan. Jakarta: Direktorat Jenderal Penataan Ruang Departemen Pekerjaan Umum.

Pradipta, I. G. A., Sarwadana, S. M., \& Pradnyawathi, N. L. M. (2018). Persepsi dan preferensi masyarakat terhadap taman rekreasi bantaran Sungai Loloan Sanur. Jurnal Arsitektur Lansekap, 4(2), 194.

Satwiko, P. 2009. Pengertian Kenyamanan Dalam Suatu Bangunan. Yogyakarta, Wignjosoebroto.

Sudjana, D. 2001. Metode Statistika. Tarsito. Bandung.

Sugiyono. 2017. Metode Penelitian Kuantitatif, Kualitatif, dan R\&D. Bandung: Alfabeta. 